\title{
The Role of Nutrition Care Process in Addressing Health Disparities in End Stage Renal Disease
}

\author{
Yingying Yip ${ }^{1}$, Devon Reilley ${ }^{1}$, Thomas V Fungwe ${ }^{2}$, Avis Graham², Oyonumo E Ntekim², Linda Thompson² and \\ Chimene Castor ${ }^{2 *}$ \\ ${ }^{1}$ Students of Dietetics, Department of Nutritional Sciences, College of Nursing and Allied Health, Howard University, USA \\ ${ }^{2}$ Department of Nutritional Sciences, USA \\ Submission:March 08, 2016; Published: April 14, 2016 \\ *Corresponding author: Chimene Castor, EdD, RDN, LDN, CHES, Department of Nutritional Sciences, Howard University, USA Tel: 202-806-5657; \\ Email: chimene.castor@Howard.edu
}

\begin{abstract}
Background: Approximately 23 million Americans have some form of chronic kidney disease, with African Americans having an incidence of end stage renal disease (ESRD) of 3.5 times higher than that of white Americans. The nutritional status of ESRD patients is a crucial issue in the disease progression. The management of ESRD requires significant lifestyle adjustments (i.e. frequent dialysis sessions and dietary restrictions) that often result in noncompliance, which in turn contributes to poorer nutritional status and health outcome.

Objective: The objective of this study was to evaluate the nutritional status of an ESRD patient using current nutrition evidence-based guidelines.

Design: Patient data was collected from medical records, and by interviewing the nurse and patient. The Nutrition Care Process was used in this study.

Subjects/Participants: A 49 year old African American female with past medical history of hypertension, type 2 diabetes mellitus, dyslipidemia, and ESRD on dialysis. Patient was admitted for left ankle fracture and dislocation status post fall.

Nutrition Diagnosis: Two nutrition problems were identified: Limited adherence to nutrition related recommendations; Impaired nutrient utilization

Intervention: Provided nutrition education focusing on low potassium food alternatives; Increased adherence to nutrition recommendation by involving patient in the nutrition care process.

Main Outcome Measure: Adherence and acceptance of nutrition recommendations, improved clinical laboratory values, and $<5 \%$ interdialytic weight gain.

Application/Conclusion: Dietitians play an important role in maintaining ESRD patients' health and quality of life. Dietary intervention aims to minimize the complications of ESRD and increase adherence and acceptance of nutrition recommendations.
\end{abstract}

Keywords: Nutrition care; Renal disease; Glomerular filtration rate

Abbreviations: Chronic Kidney Disease; GFR: Glomerular Filtration Rate; ESRD: End-Stage Renal Disease; NHANES III: Third National Health and Nutrition Examination Survey

\section{Introduction}

Chronic kidney disease (CKD) is a condition characterized by a gradual loss of kidney function over time. The National Kidney Foundation classifies patients with chronic kidney disease into five stages according to their glomerular filtration rate (GFR), which is the rate in which blood passes through the glomeruli (tiny filters in the kidney). Chronic kidney disease is defined as a GFR of less than or equal to $60 \mathrm{~mL} / \mathrm{min} / 1.73 \mathrm{~m} 2$ that is documented to 3 or more months [1]. Patients with chronic kidney disease stages 3 to 5 are at increased risk of progressing to end-stage renal disease (ESRD) or dying before the development of ESRD compared with patients with less severe chronic kidney disease. There are many factors that put individuals at risk for developing chronic kidney disease. Some of the most common risk factors include diabetes mellitus and high blood pressure. Chronic kidney disease, due to its high morbidity and mortality, is a major public health issue. A 2003 analysis of data from the Third National Health and Nutrition Examination Survey (NHANES III) reported that chronic kidney disease affects 19.2 million of the US adult population. Aging, the rising prevalence of 
obesity, hypertension, and type 2 diabetes are all major risk factors for chronic kidney disease (Figure 1). Regarding ethnicity, AfricanAmericans, Native Americans, and Hispanic Americans are at least two times as likely to develop chronic kidney disease compared to white Americans [2]. African Americans are disproportionately affected by ESRD. In 2007, over 500,000 Americans received ESRD treatment, with African Americans having an incidence of ESRD 3.7 times higher than that of Caucasians. One study has shown that African-Americans with ESRD also have higher mortality rates than white Americans, even after adjusting for socio-demographic and clinical factors. There are several factors that are believed to play an important role in this disparity, for example, low socioeconomic status, lack of knowledge on dialysis treatment, and negative perceptions of the disease. Low socioeconomic status influences African Americans' increased risk of CKD through multiple ways. It may contribute to racial disparities in CKD because of the greater prevalence of poverty among African Americans [3]. In addition, African American with low SES also report more costrelated non-adherence to prescribed medication than others. Lack of knowledge related to dialysis treatment processes is another factor that contributes to the health disparities in ESRD in African Americans. This knowledge deficit has a negative impact on health outcomes, quality of life, and medical adherence. The third factor is negative perceptions about the disease. One study has reported that African- Americans have higher negative perceptions of personal intervention or medical treatment controlling their ESRD. All these factors affect health outcomes of ESRD in African Americans and different therapeutic approaches may be required for this population.

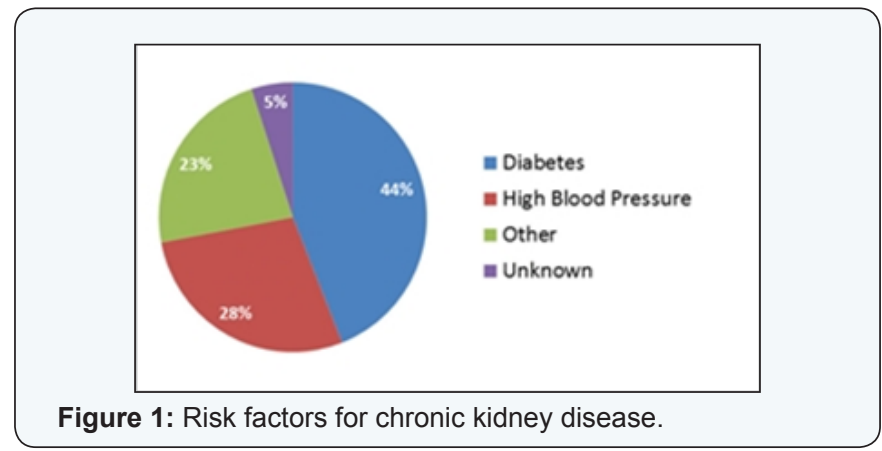

The following case presentation illustrates the importance of recognizing ESRD and identifies lifestyle modifications that can be used to manage the disease. The assessment, intervention, monitoring, and evaluation were done in an inpatient setting by a dietetic intern trained to conduct dietary assessments. The case study was conducted and prepared in accordance with the Health Insurance Portability and Accountability Act.

\section{Method}

The electronic and paper medical records were viewed. After all pertinent information was collected from the medical records, the nurse was interviewed. Lastly, the patient was interviewed and asked questions regarding food intake, appetite, weight loss, usual meal patterns, and other information necessary for a thorough nutritional assessment. After completing the assessment, a nutrition diagnosis was stated, followed by development of the nutrition intervention. Evaluation criteria were developed in order to monitor the patient's progress.

\section{Patient Profile}

The patient is a 49-year-old, morbidly obese African American female. She was admitted to hospital for left ankle fracture and dislocation status post fall. Her past medical history includes hypertension, type 2 diabetes mellitus, dyslipidemia, and ESRD. She is dialysis dependent for 7 years.

\section{Nutrition Assessment}

Table 1: Patient's anthropometric data, nutrient needs, nutrition focused physical examination, and social and family history.

\begin{tabular}{|c|c|}
\hline Anthropometric Data & $\begin{array}{c}\text { Height: } 69 \text { inches } \\
\text { BMI }=54.5 \\
\text { Ideal body weight }=145 \mathrm{lb} \\
\% \text { Ideal body weight }=253 \% \\
\text { Pre-dialysis weight }=378 \mathrm{lb} \\
\text { Post- dialysis weight }=367 \mathrm{lb} \\
\text { Interdialytic weight gain }=11 \mathrm{lb} / \\
3 \% \text { (goal }<5 \% \text { ) }\end{array}$ \\
\hline Nutrient Needs & $\begin{array}{c}\text { Estimated energy needs: } 25- \\
\text { 27kcal } / \mathrm{kg} \\
(25-27 \mathrm{kcal}) * A B W(90.9 \mathrm{~kg})= \\
2273 \mathrm{kcal}-2454 \mathrm{kcal} \\
\text { Estimated Protein needs: } 1.2 \mathrm{~g} / \\
\text { kg(ABW) }=109 \mathrm{~g} / \mathrm{day} \\
\text { Fluid: output }+1000 \mathrm{ml}= \\
(0)+1000 \mathrm{ml}=1000 \mathrm{ml}\end{array}$ \\
\hline Physical Exam & $\begin{array}{l}\text { Vital: BP 155/91, Temp. } 98.6 \\
\text { Alert and oriented x3 } \\
\text { Dyspnea with mild exertion and } \\
\text { orthopnea (resolved) Obese, } \\
\text { active bowel sound } \\
\text { Skin intact } \\
\text { Left eye blindness } \\
\text { Missing teeth - no chewing/ } \\
\text { swallowing issues AV graft left } \\
\text { arm } \\
\text { Fracture and dislocated left } \\
\text { ankle, pain scale } 9 / 10\end{array}$ \\
\hline Social and Family History & $\begin{array}{l}\text { Smokes } 1 \text { pack cigarette /day } \\
\text { for } 30 \text { years Denies alcohol, } \\
\text { recreational drug use } \\
\text { Lives at home with } 8 \text { y/o son and } \\
\text { fiancee On disability } \\
\text { Family Hx: Parents - HTN, DM2, } \\
\text { heart disease }\end{array}$ \\
\hline
\end{tabular}


Table 2: Biochemical Data.

\begin{tabular}{|c|c|c|c|c|}
\hline Labs & $\begin{array}{c}\text { Normal } \\
\text { Range }\end{array}$ & $10 / 10$ & $10 / 9$ & $10 / 8$ \\
\hline Sodium & $\begin{array}{c}135-148 \\
\mathrm{mEq} / \mathrm{L}\end{array}$ & $134 \mathrm{~L}$ & 135 & $132 \mathrm{~L}$ \\
\hline Potassium & $3.5-5.3 \mathrm{mEq} / \mathrm{L}$ & 4.4 & 4.6 & 4.5 \\
\hline Magnesium & $1.7-2.5 \mathrm{mg} / \mathrm{dL}$ & 2.1 & 2.2 & 2.1 \\
\hline Calcium & $\begin{array}{c}8.5-10.6 \mathrm{mg} / \\
\mathrm{dL}\end{array}$ & $8.3 \mathrm{~L}$ & $8.3 \mathrm{~L}$ & 8.7 \\
\hline $\begin{array}{l}\text { Total } \\
\text { Protein }\end{array}$ & $6.2-8.3 \mathrm{~g} / \mathrm{dL}$ & & 6.4 & 7.3 \\
\hline Albumin & $3.2-5.5 \mathrm{~g} / \mathrm{dL}$ & & $2.8 \mathrm{~L}$ & 3.2 \\
\hline Glucose & $70115 \mathrm{mg} / \mathrm{dL}$ & $239 \mathrm{H}$ & $264 \mathrm{H}$ & $147 \mathrm{H}$ \\
\hline Phosphorus & $2.5-4.5 \mathrm{mg} / \mathrm{dL}$ & $4.9 \mathrm{H}$ & $5.9 \mathrm{H}$ & $5.0 \mathrm{H}$ \\
\hline BUN & 7-25 mg/dL & $29 \mathrm{H}$ & $57 \mathrm{H}$ & $39 \mathrm{H}$ \\
\hline Creatinine & $0.6-1.2 \mathrm{mg} / \mathrm{dL}$ & $9.2 \mathrm{H}$ & $13.8 \mathrm{H}$ & $10.8 \mathrm{H}$ \\
\hline GFR & $5 \mathrm{~L}$ & $3 \mathrm{~L}$ & $5 \mathrm{~L}$ & GFR \\
\hline
\end{tabular}

Table 3: Medications.

\begin{tabular}{|c|c|c|}
\hline Medications & Action & Side Effect \\
\hline Lipitor 40mg HS & Antihyperlipidemic & Nausea, dyspepsia \\
\hline $\begin{array}{c}\text { Carvedilol 25mg } \\
\text { Q12H }\end{array}$ & Antihypertensive & N/V, $\uparrow$ Glu, BUN, Crea \\
\hline Promethazine & Antihistamine & $\begin{array}{c}\text { Dry mouth, N/V, } \\
\text { constipation }\end{array}$ \\
\hline $\begin{array}{c}\text { Diphenhydramine } \\
\text { Q6H PRN }\end{array}$ & Antihistamine & $\begin{array}{c}\text { Dry mouth/throat, } \\
\text { constipation, } \\
\text { epigastric distress }\end{array}$ \\
\hline $\begin{array}{c}\text { Hydralazine Q12H } \\
\text { 100mg }\end{array}$ & Antihypertensive & $\begin{array}{c}\text { Anorexia, } \downarrow \text { renal } \\
\text { function }\end{array}$ \\
\hline Lactulose & Laxative & $\begin{array}{c}\text { Drug } \uparrow \text { abs od Ca } \\
\text { and Mag, } \uparrow \text { glu in } \\
\text { diabetics }\end{array}$ \\
\hline Insulin & & \\
\hline
\end{tabular}

Patient denied alcohol consumption. She reported that she had good appetite, usually $75-100 \%$ intake of meals. She did not have any food allergies. Pt reported that she was being overwhelmed by and non-compliant to renal diet. She liked high potassium foods such as potato and orange juice. She also reported that she has knowledge on ways to reduce potassium content in foods such as leaching but has no interest in applying it because it required too much work for her. Patient's anthropometric data, nutrient needs, nutrition focused physical examination, and social and family histories are listed in Table 1. Biochemical data is listed in Table 2. Medications are listed in Table 3.

\section{Nutrition diagnosis}

Based on the assessment, and considering the nutrition diagnostic labels listed for specific nutrient discrepancies, the following Nutrition Diagnostic Statements were developed:

- Limited adherence to nutrition related recommendations (NB-1.6) related to unwillingness to apply information as evidenced by pt. stated "there are more foods that I cannot eat than I can eat" and reported lack of compliance with plan and consuming high potassium foods.

- Impaired nutrient utilization (NC-2.1) related to T2DM and ESRD as evidenced by elevated glucose (239), BUN (29), creatinine (9.2), and phosphorus (4.9), and depleted calcium (8.3), RBC (3.17), and H/H (9/27.9).

\section{Nutrition intervention}

The first goal for this patient was to increase adherence to nutrition recommendations by involving patient in the nutrition care process. In order to reach this goal, the patient was educated on low potassium foods, specifically alternatives to the high potassium foods she currently consumes. The patient was encouraged to decrease high potassium food consumption and the negative consequences of a high potassium diet were discussed. She was provided with Low-Potassium Nutrition Therapy handout from the Nutrition Care Manual. The second goal for this patient was to stabilize electrolytes $(\mathrm{Na}, \mathrm{K}, \mathrm{Mg}, \mathrm{Cl})$, blood glucose, hydration status, and maintain bone density. In order to reach this goal, the intervention for this patient was to build on her existing knowledge by providing education materials on carbohydrate controlled renal diet. She was provided with lists of high and low $\mathrm{Na}, \mathrm{K}, \mathrm{P}$ foods (large font). She was also provided with food alternatives and tips for lowering $\mathrm{Na}, \mathrm{K}$, and P intake. Her need for EPO and Calcitriol was considered to maintain bone density. The patient's nutrition prescription: $2200 \mathrm{kcal}$ Carbohydrate Controlled Renal Diet (45$50 \%$ CHO) with $1000 \mathrm{~mL}$ fluid restriction.

\section{Stages of change and motivational interviewing}

The patient is currently in contemplation stage which means that the patient is aware that a problem exists but has no serious thought or commitment to making a change and keeps putting it off. The goal for patient in the stage is to increase motivation and confidence to perform the behavior. Therefore, motivational interviewing technique was used during interview to increase the patient's readiness to change. Three principles were used: express empathy, develop discrepancy, and support self-efficacy. Patient's feeling and experience were clarified and amplified. Pros and Cons of current behavior and behavior change were discussed with the patient. Patient's hope was also reinforced by encouragement.

\section{Nutrition monitoring and evaluation}

Adherence to nutritional recommendations and patient's readiness to change was monitored. The criteria are that the patient's 24 hour recall will be in compliance with nutrition recommendations. Her lab values were also monitored specifically electrolytes, glucose, and phosphorus. The goal is for these labs to trend toward within normal limits. Lastly, hydration status was monitored. The criteria are for the patient to have less than $5 \%$ interdialytic weight gain. Any weight changes larger than this may cause hemodynamic instability. 


\section{Discussion}

The burden of advanced CKD disproportionately affects African Americans. The high incidence of ESRD among them has been attributed to the high prevalence of major CKD risk factors including hypertension, diabetes, obesity, and low socioeconomic status. Low socioeconomic status may affect end-stage renal disease risk and outcomes through social and psychosocial factors, which in turn manifest as unhealthy choices [3]. The patient of this case study has all of the major CKD risk factor and also receives food assistance. Barriers for her to change also include disability, unemployment, and having an 8-year-old son. Health disparities such as low socioeconomic status and barriers to change may contribute to her being non-compliance to nutrition recommendation.

Non-compliance with the prescribed diet and fluid restrictions is common among patients receiving hemodialysis. The study of Kugler et al. [4] has shown that many patients had difficulty following diet $(81.4 \%)$ and fluid $(74.6 \%)$ restrictions. Smokers were at highest risk for non-adherence. Higher levels of interdialysis weight gain were also associated with non-adherence. According to a study, more than one third of patients were noncompliant with at least one dietary restriction. Phosphorus dietary restrictions were the most commonly seen. In addition, the results suggested that patients with better knowledge about dietary restrictions were less likely to be compliant [4]. Patients with better knowledge about the medical complications of noncompliance were also less likely to be compliant for dietary restrictions. The study concluded that Instead of the traditional approach of information-giving, effective educational methods that focus on motivating patients to comply with dietary restrictions are needed to improve compliance [5]. It is also important for the health care professionals to assess where the patient is with regard to stages of change because it may assist them in better matching interventions that build patients' selfefficacy [6].

\section{Limitation}

The key limitation of this study is generalization of the conclusion. Since the case study was conducted with one subject, the results of the study may not be representative of the population. In addition, nutrition follow-ups were not conducted with the subject. Patient progression was not assessed.

\section{Conclusion}

Dietary assessment is of paramount importance in providing optimal care to CKD patients, and in particular to dialysis patients [7]. The nutritional status of ESRD patients is a crucial issue in the disease progression. The management of ESRD requires significant lifestyle adjustments (i.e. frequent dialysis sessions and dietary restrictions) that often result in noncompliance, which is turn contributes to poorer nutritional status and health outcomes. Dietitians play an important role in maintaining ESRD patients' health and quality of life. Dietary intervention aims to minimize the complications of ESRD and increase adherence and acceptance to nutrition recommendations.

\section{References}

1. National Kidney Foundation (2015) About Chronic Kidney Disease.

2. Coresh J, Selvin E, Stevens LA, Manzi J, Kusek JW, et al. (2007) Prevalence Prevalence of chronic kidney disease in the United States. JAMA 298(17): 2038-2047.

3. Johns TS, Crews DC (2013) Racial and socioeconomic disparities in end-stage renal disease in the United States. OA Nephrology 1(2): 18.

4. Kugler C, Vlaminck H, Haverich A, Maes B (2005) Nonadherence with diet and fluid restrictions among adults having Hemodialysis. J Nurs Scholarsh 37(1): 25-29.

5. Durose CL, Holdsworth M, Watson V, Przygrodzka F (2004) Knowledge of dietary restrictions and the medical consequences of noncompliance by patients on hemodialysis are not predictive of dietary compliance. J Am Diet Assoc 104(1): 35-41.

6. Elliott JO, Ortman C, Almaani S, Lee YH, Jordan K (2015) Understanding the associations between modifying factors, individual health beliefs, and hemodialysis patients' adherence to a low-phosphorus diet. J Ren Nutr 25(2): 111-120.

7. Bross R, Noori N, Kovesdy CP, Murali SB, Benner D, et al. (2010) Dietary assessment of individuals with chronic kidney disease. Semin Dial 23(4): 359-364. 